\title{
RMetS
}

Royal Meteorological Society

\section{Southern Hemisphere atmospheric circulation response to the El Chichón and Pinatubo eruptions in coupled climate models}

\author{
Alexey Yu. Karpechko, ${ }^{\mathrm{a}, \mathrm{b} \star}$ Nathan P. Gillett, ${ }^{\mathrm{c}}$ Mauro Dall'Amico ${ }^{\mathrm{d}, \mathrm{e}}$ and Lesley J. Gray ${ }^{\mathrm{f}}$ \\ ${ }^{a}$ Climatic Research Unit, School of Environmental Sciences, University of East Anglia, Norwich, UK \\ ${ }^{\mathrm{b}}$ Arctic Research, Finnish Meteorological Institute, Helsinki, Finland \\ ${ }^{c}$ Canadian Centre for Climate Modelling and Analysis, Environment Canada, Victoria, BC, Canada \\ ${ }^{\mathrm{d}}$ Deutsches Zentrum für Luft- und Raumfahrt, Institut für Physik der Atmosphäre, Oberpfaffenhofen, Germany \\ e Present address: Astrium GmbH, Ottobrunn, Germany \\ ${ }^{\mathrm{f}}$ National Centre for Atmospheric Sciences - Climate Directorate, Meteorology Dept., University of Reading, UK \\ ${ }^{\star}$ Correspondence to: Alexey Yu. Karpechko, Arctic Research Centre, Finnish Meteorological Institute, PO Box 503, \\ FI-00101 Helsinki, Finland. E-mail: alexey.karpechko@fmi.fi
}

\begin{abstract}
We study the response of the Southern Hemisphere circulation to the 1982 eruption of El Chichón and 1991 eruption of Pinatubo volcanoes in a suite of up-to-date coupled climate models. We find a significant response in austral spring and autumn in the years following the eruptions, which consists of a stronger stratospheric polar vortex and lowered sea-level pressure over the Antarctic, both consistent with the positive phase of the Southern Annular Mode. The seasonality of the response may be explained in terms of zonal flow-planetary wave interactions. This dynamical response is inconsistent with the observational reanalyses in the polar stratosphere in spring, but not in the troposphere where the internal variability is large compared to the magnitude of the response. Copyright (c) 2010 Royal Meteorological Society
\end{abstract}

Key Words: $\quad$ volcanic eruptions; stratosphere; Southern Annular Mode; climate variability

Received 28 January 2010; Revised 6 April 2010; Accepted 6 July 2010; Published online in Wiley Online Library 1 October 2010

Citation: Karpechko AYu, Gillett NP, Dall'Amico M, Gray LJ. 2010. Southern Hemisphere atmospheric circulation response to the El Chichón and Pinatubo eruptions in coupled climate models. Q. J. R. Meteorol. Soc. 136: 1813-1822. DOI:10.1002/qj.683

\section{Introduction}

Sulphur dioxide injected into the stratosphere by large volcanic eruptions is converted to sulphate aerosols that remain there for a few years, altering the radiative budget of the atmosphere. Aerosols reflect solar visible radiation causing cooling at the Earth's surface and absorb solar near-infrared and terrestrial radiation causing warming of the stratosphere (Robock, 2000). Known impacts of large eruptions that inject sulphur dioxide into the stratosphere also include a strengthening of the Northern Hemispheric $(\mathrm{NH})$ stratospheric polar vortex and the tropospheric midlatitude westerly winds in the winters following the eruption (Graf et al., 1993; Kodera, 1994). The strengthened extratropical zonal circulation corresponds to a positive phase of the Northern Annular Mode (NAM: Thompson and Wallace, 2000). The NH dynamical response is reproduced by climate models, albeit with a weaker magnitude (Stenchikov et al., 2006).

Whether or not a dynamical response to large volcanic eruptions exists in the Southern Hemisphere ( $\mathrm{SH}$ ) remains unclear. Marshall (2003) and Roscoe and Haigh (2007) used a station-based Southern Annular Mode (SAM) index (Marshall, 2003) and found a negative SAM response to volcanic forcing, corresponding to a positive sea-level pressure anomaly over the Antarctic. Crooks and Gray (2005) in a regression analysis of the reanalysis data from the European Centre for Medium-Range Weather Forecasts (ERA-40) also found a weakened annual-averaged wind response in the $\mathrm{SH}$ troposphere, suggesting a negative SAM response. However Robock et al. (2007) studied the SH circulation after the Pinatubo eruption in the ERA-40 and National Centers for Environmental Prediction/National Center for Atmospheric Research reanalysis (NNR) datasets 
Table I. Description of the coupled models used in this study

\begin{tabular}{lcccc}
\hline Model name and country & N runs & Levels & Top & Volcanic aerosol \\
\hline GFDL CM2.0, USA & 3 & 24 & $3 \mathrm{hPa}$ & Sato et al. (1993) Stenchikov et al. (1998) \\
GFDL CM2.1, USA & 3 & 24 & $3 \mathrm{hPa}$ & Sato et al. (1993) Stenchikov et al. (1998) \\
GISS-EH, USA & 5 & 20 & $0.1 \mathrm{hPa}$ & Sato et al. (1993) \\
GISS-ER, USA & $4(5)^{\mathrm{a}}$ & 20 & $0.1 \mathrm{hPa}$ & Sato et al. $(1993)$ \\
MIROC3.2 (hires), Japan & 1 & 56 & $1 \mathrm{hPa}$ & Sato et al. $(1993)$ \\
MIROC3.2 (medres), Japan & 3 & 20 & $10 \mathrm{hPa}$ & Sato et al. $(1993)$ \\
CCSM3.0, USA & 8 & 26 & $2.2 \mathrm{hPa}$ & Ammann et al. $(2003)$ \\
PCM, USA & 4 & 18 & $2.9 \mathrm{hPa}$ & Ammann et al. $(2003)$ \\
HadGEM1, UK & 4 & 38 & $3.1 \mathrm{hPa}$ & Sato et al. $(1993)$ \\
HadGEM1 QBO, UK & 6 & 38 & $3.1 \mathrm{hPa}$ & Sato et al. (1993)
\end{tabular}

${ }^{a}$ Four simulations are available for upper-air variables and five for surface variables.

b Simulations with prescribed interannual ozone variability and QBO in zonal winds.

and in the Goddard Institute for Space Studies (GISS) Model-E coupled climate model and found no response in the SAM.

Robock et al. (2007) concentrated on austral winter and looked only at the output of one climate model. In this paper we re-examine the dynamical response of the $\mathrm{SH}$ circulation to large volcanic eruptions using the outputs of several atmosphere-ocean coupled climate models and show that the models exhibit a significant dynamical response to the eruptions in austral spring and autumn similar to that observed and simulated in the $\mathrm{NH}$ in winter. The model results are compared with the observed response, and possible mechanisms are discussed to explain the discrepancy between the modelled and observed responses.

\section{Data and Methodology}

We use data from nine coupled atmosphere-ocean general circulation models available from the World Climate Research Programme's (WCRP's) Coupled Model Intercomparison Project phase 3 (CMIP3) dataset at https://esgcet.llnl.gov:8443/. For both GISS-E models data were downloaded directly from the GISS server (ftp://data.giss.nasa.gov/pub/pcmdi/). Volcanic forcing in the CMIP3 models is described in Stenchikov et al. (2006). Only a subset of nine CMIP3 models that include volcanic forcing in their simulations of the twentieth-century climate is used (see Table I). In addition to the CMIP3 dataset we make use of nine HadGEM1 model simulations with anthropogenic and natural forcings including volcanic aerosol: the baseline and the baseline+ozone + QBO threemember ensembles described in Dall'Amico et al. (2009a) and a further set of three baseline + ozone $+\mathrm{QBO}$ simulations conducted on a different computing facility. Volcanic forcing in these simulations is identical to the HadGEM1 simulation of the twentieth-century climate from the CMIP3 dataset, but a more realistic ozone forcing which includes observed interannual ozone variability, and also a zonal wind relaxation to the Quasi-Biennial Oscillation (QBO) in zonal winds, are implemented in the six baseline+ozone+QBO simulations (HadGEM1 QBO). Altogether data from 41 simulations are available for upper-air variables and 42 simulations are available for surface variables. The multimodel ensemble mean (MULTI) is calculated by averaging across all available simulations. We also examine the ERA40 (Uppala et al., 2005), and the NNR (Kalnay et al.,
1996) datasets. The Hadley Centre Sea Ice and Sea Surface Temperature dataset (Rayner et al., 2003) is used to calculate observed El Niño 3.4 index.

We concentrate on the response to two eruptions: El Chichón (4 April 1982) and Pinatubo (15 June 1991) since these are the eruptions with the largest radiative forcing during the twentieth century (see Table II of Stenchikov et al., 2006), and they both occurred during the period of satellite observations. Statistical significance of the ensemble mean anomalies is evaluated using a one-sample twosided $t$-test assuming each model simulation represents an independent sample. Statistical significance of the difference between the models and the reanalyses after the eruptions is evaluated using a two-sample two-sided $t$-test assuming each post-volcanic year and each model simulation represent independent samples. Since different models have different numbers of simulations, the multi-model ensemble means may be biased towards models that have a larger number of simulations. However, the main conclusions of this study do not depend on whether the multi-model ensembles are composed of the model means or of the individual simulations.

\section{Results}

Figure 1 shows time series of monthly mean anomalies of the $\mathrm{SH}$ low-latitude $\left(0^{\circ}-40^{\circ} \mathrm{S}\right)$ temperature at $50 \mathrm{hPa}$ and at the surface as well as the $\mathrm{SH}$ polar cap $\left(60^{\circ} \mathrm{S}-90^{\circ} \mathrm{S}\right)$ $50 \mathrm{hPa}$ geopotential height and mean-sea-level pressure (MSLP) for the period 1979-1999 in MULTI, in the HadGEM1 QBO ensemble, and in the reanalyses. The anomalies were calculated by subtracting linear trends for the period 1979-1999 for each month separately. A two-year period following each eruption was excluded from the trend calculations. The models reproduce the temperature response to the radiative effects of volcanic aerosol in low latitudes. The warming of the low-latitude stratosphere caused by the absorption of solar near-infrared and terrestrial radiation by the volcanic aerosol lasts for 2-3 years after the eruptions (Figure 1(a)). The simulated warming appears larger than that in the reanalyses during the first year after the Pinatubo eruption. Analysis of the vertical structure of the warming (Figure 2) shows that this overestimation is largest at $60 \mathrm{hPa}$. Stenchikov et al. (2006) found that differences across the models in simulating the warming are understandable in terms of the 
(a)

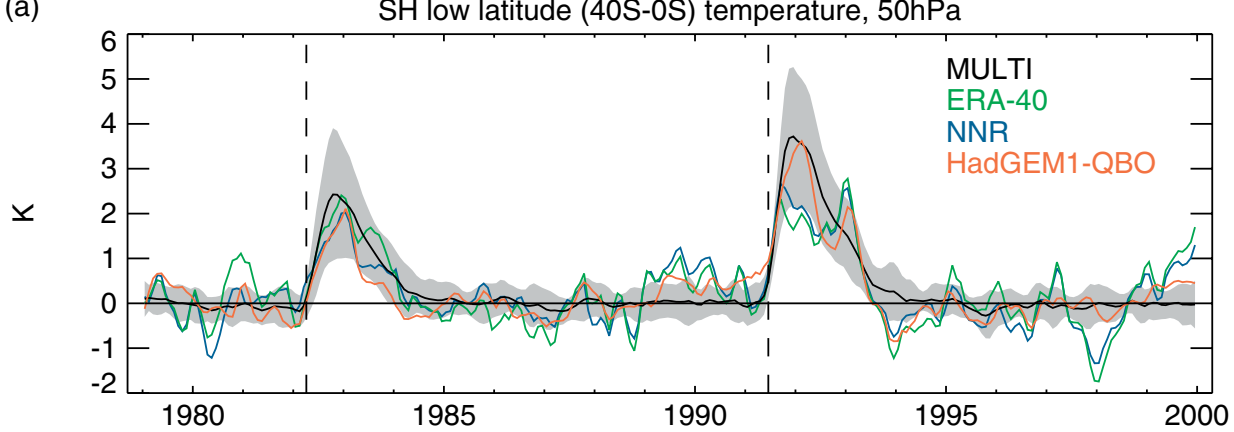

(b)

SH low latitude (40S-0S) surface temperature

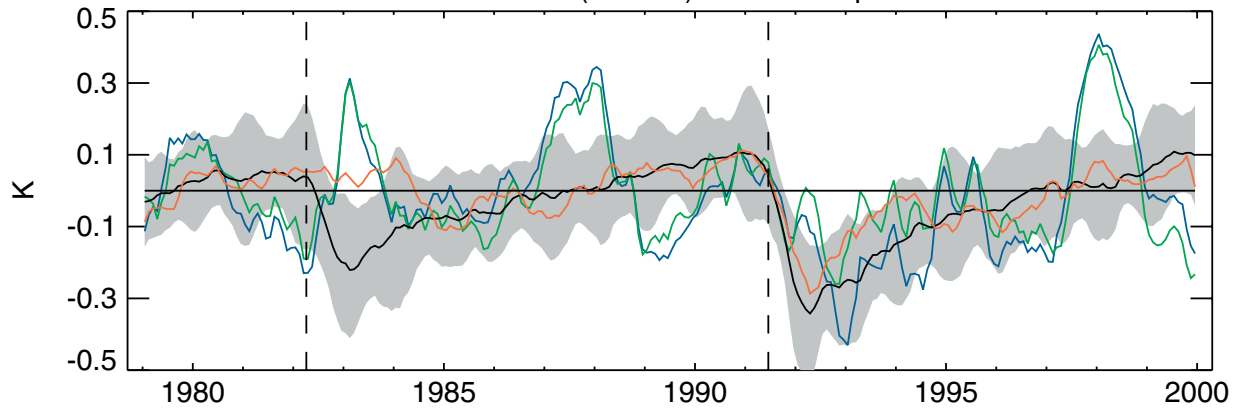

(c)

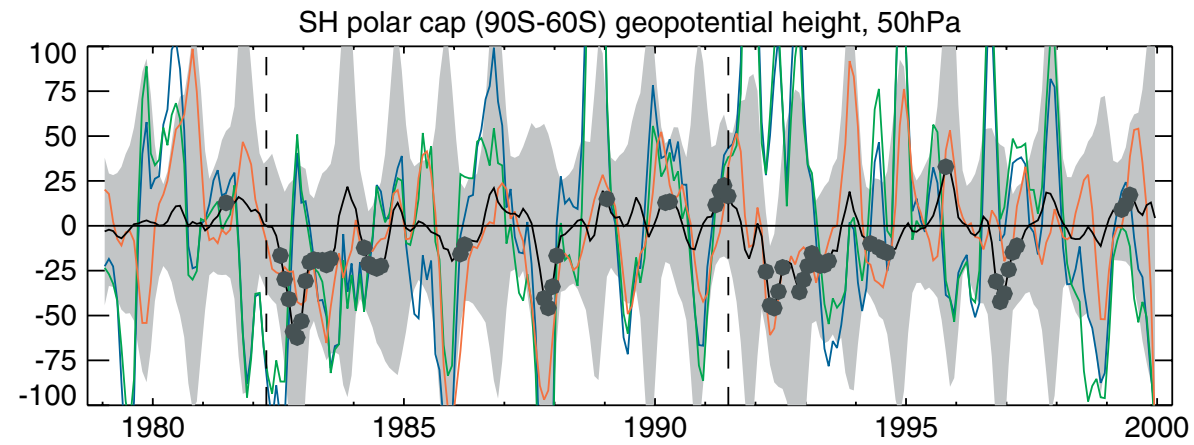

(d)

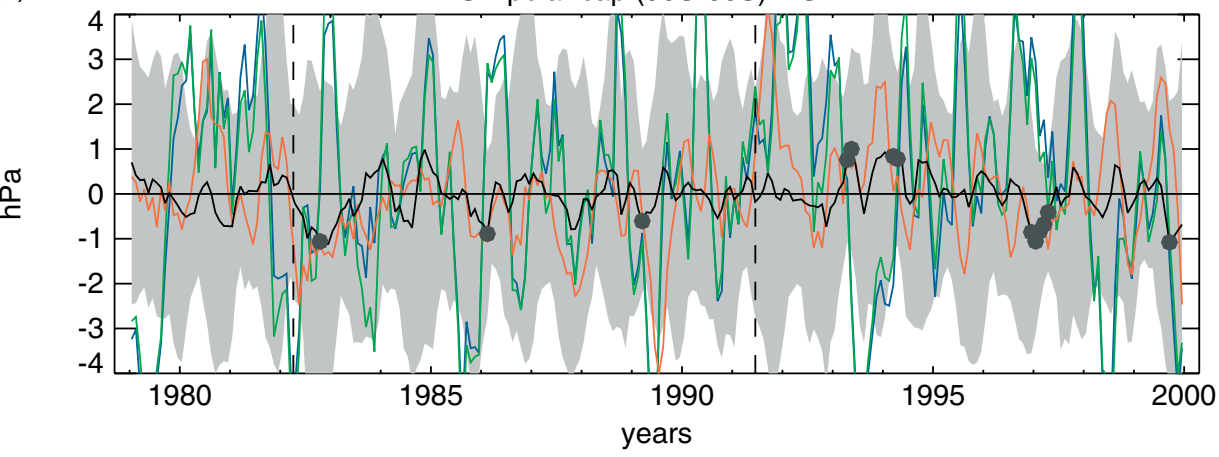

Figure 1. Time series of detrended anomalies of the SH low-latitude $\left(0^{\circ}-40^{\circ} \mathrm{S}\right)$ temperature (a) at $50 \mathrm{hPa}$ and (b) at the surface; and the $\mathrm{SH}$ polar cap $\left(60^{\circ} \mathrm{S}-90^{\circ} \mathrm{S}\right)$ (c) $50 \mathrm{hPa}$ geopotential height, and (d) MSLP. Anomalies are smoothed by a 3-month moving average. Shaded area indicates $1 \mathrm{SD}$ across individual simulations. Grey circles in (c) -(d) highlight anomalies significant with $p<0.05$. Vertical dashed lines indicate times of the volcanic eruptions.

treatment of the aerosol properties. The largest warming is simulated by the Model for Interdisciplinary Research on Climate (MIROC) models, likely because they assume a fixed effective radius of particles representative of the background aerosol, which leads to more near-infrared absorption. On the other hand the GISS and Geophysical Fluid Dynamics Laboratory (GFDL) models, which assume a more realistic volcanic aerosol radius varying in space and time, simulate a more realistic warming. Despite these differences, the warming in MULTI is not inconsistent with the reanalyses throughout the lower stratosphere after both the eruptions in the first two years following an eruption according to a $t$ test. Only at $10 \mathrm{hPa}$ where the post-volcanic anomalies in the reanalyses are negative do the models appear inconsistent 

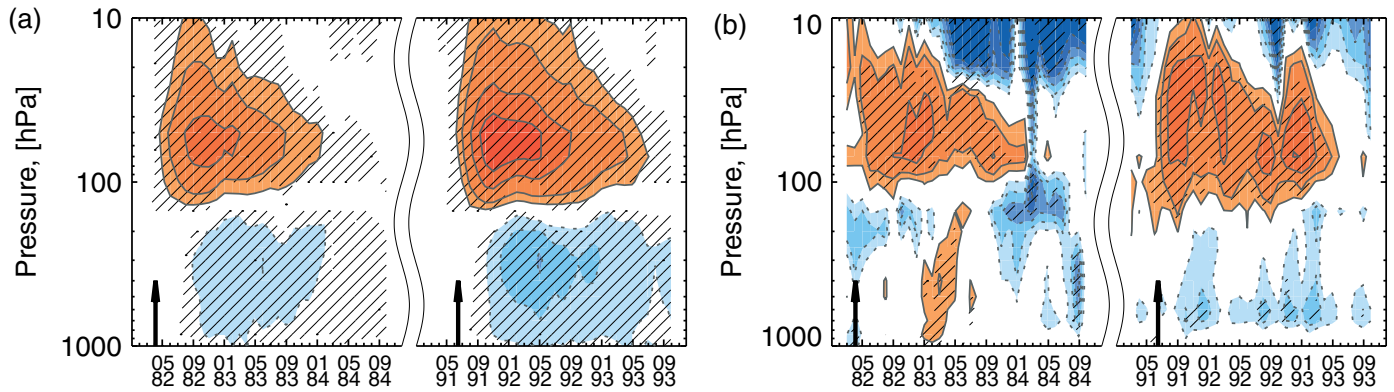

Figure 2. Detrended zonal mean temperature (K) in the SH low latitudes $\left(0^{\circ}-40^{\circ} \mathrm{S}\right)$ after the El Chichón and Pinatubo eruptions in (a) MULTI and (b) ERA-40. Contours are drawn at $-1.25,-1,-0.75,-0.5,-0.25,0.5,1,2$ and $3 \mathrm{~K}$. Negative contours are dotted. Hatching in (a) indicates anomalies significant with $p<0.05$ and in (b) anomalies exceeding $1.5 \mathrm{SD}$ of the respective time series. Arrows indicate times of the volcanic eruptions. This figure is available in colour online at wileyonlinelibrary.com/journal/qj
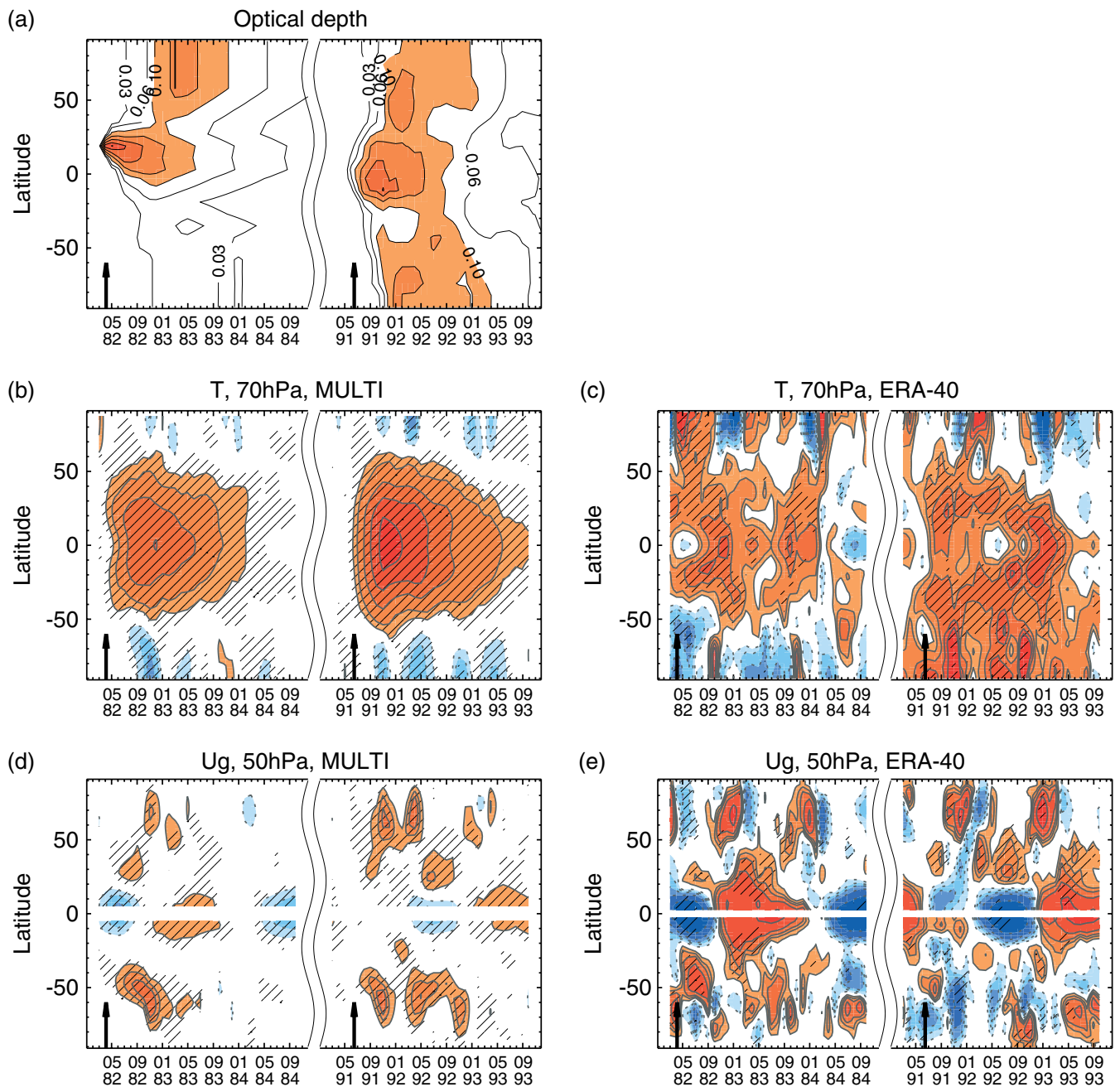

Figure 3. (a) Zonal mean stratospheric aerosol optical thickness at $550 \mathrm{~nm}$; detrended zonal mean (b) - (c) $70 \mathrm{hPa}$ temperature (K) and (d) - (e) 50 hPa geostrophic wind anomalies $\left(\mathrm{m} \mathrm{s}^{-1}\right)$, after the El Chichón and Pinatubo eruptions in (b),(d) MULTI and (c),(e) ERA-40. Contours are drawn at (b),(d) $\pm 0.5, \pm 1, \pm 2, \pm 3 \mathrm{~K}$ and (c),(e) $\pm 1, \pm 2, \pm 3, \pm 5, \pm 10 \mathrm{~m} \mathrm{~s}^{-1}$. Negative contours are dotted. Hatching in (b),(d) indicates anomalies significant with $p<0.05$ and in (c),(e) anomalies exceeding $1.5 \mathrm{SD}$ of the respective time series. Arrows indicate times of the volcanic eruptions. This figure is available in colour online at wileyonlinelibrary.com/journal/qj

with the ERA-40 but not with the NNR according to a $t$-test.

Figure 1(b) shows low-latitude surface temperatures in the models and in the reanalyses. The observed temperature variability is strongly modulated by the El Niño/La Niña events (e.g. Turner, 2004). The simulated low-latitude surface temperatures in MULTI drop after the eruptions due to reduced solar radiation, whereas the observed anomalies are positive after the El Chichón eruption due to the 1982/1983 El Niño event and only slightly negative during the first year after the Pinatubo eruption due to the 1991/1992 El Niño event. The HadGEM1-QBO ensemblemean surface temperature drops after the Pinatubo eruption but not after the El Chichón eruption. This feature is likely associated with the QBO as discussed in Dall'Amico et al. (2009b).

In the high-latitude stratosphere, significant negative geopotential height anomalies, indicating strengthening of 
(a)

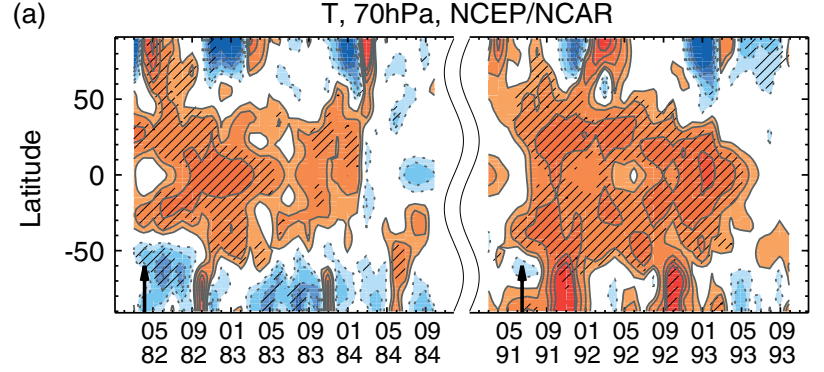

(b)

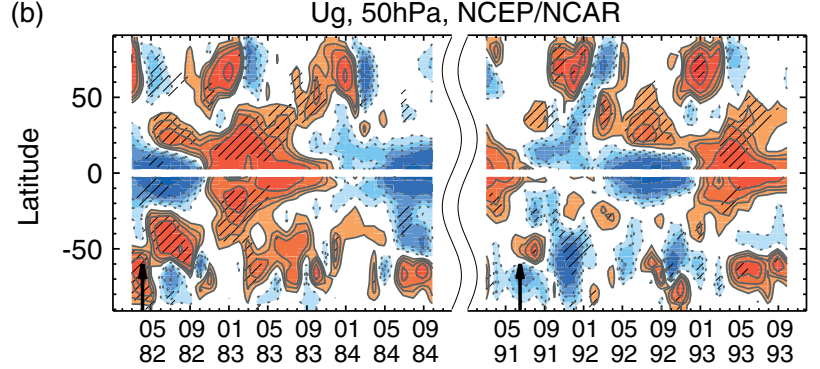

Figure 4. (a),(b) The same as Figure 3(c) and (e) but for the NNR. This figure is available in colour online at wileyonlinelibrary.com/journal/qj

the Antarctic polar vortex, are simulated following the eruptions (Figure 1(c)). The largest negative anomaly is simulated in austral spring 1982 following the El Chichón eruption. Large negative anomalies are also seen in spring and autumn 1992, the year after the Pinatubo eruption. A negative anomaly is also simulated in spring 1991 but of smaller magnitude than in the following year. The periods of the strengthening coincide with negative MSLP anomalies (Figure $1(\mathrm{~d})$ ), although the anomalies after the Pinatubo eruption do not exceed the internal variability. In the reanalyses the anomalies are positive in austral spring 1982 and after the Pinatubo eruption both in the stratosphere and in the troposphere. According to a $t$-test, the polar stratosphere response in the models in the first two springs following an eruption is inconsistent with the reanalyses with $p<0.05$ but the models are not significantly different from the reanalyses either at the surface or in the polar stratosphere in autumn.

Figure 3(a) shows zonal mean stratospheric aerosol optical thickness for the post-volcanic years described in Sato et al. (1993) (http://data.giss.nasa.gov/modelforce/strataer/) and used by the majority of the models (Stenchikov et al., 2006). The enhanced values, which are largest in the Tropics after both eruptions, indicate volcanic forcing. Figure 3(b) shows zonal mean temperature anomalies at $70 \mathrm{hPa}$. Significant cooling is simulated in the $\mathrm{SH}$ high latitudes after both eruptions maximising in spring/early summer (October-December) and in autumn (March-May). An SH high-latitude stratospheric cooling in the spring following the Pinatubo eruption similar to that shown in Figure 3(b) has been simulated in several other models (e.g. Kirchner et al., 1999; Ramachandran et al., 2000; Rozanov et al., 2002); however, it received no attention in these studies. The $\mathrm{SH}$ stratospheric westerly jet at $50 \mathrm{hPa}$ (Figure 3(d)) exhibits periods of strengthening which coincide with the periods of maximum high-latitude cooling. In ERA-40 (Figures 3(c)) the tropical warming is modulated by the QBO (Figures 3(e)) and consistent $\mathrm{SH}$ high-latitude cooling is missing. The cooling is also missing in the NNR (Figure 4). According to a $t$-test the difference between the models and the reanalyses in the polar stratosphere temperatures in the first two springs following an eruption is significant with $p<0.05$.

Figure 5 shows zonal mean geopotential height anomalies in the SH during one post-El-Chichón spring (1982) and two post-Pinatubo springs (1991 and 1992). Similar patterns are obtained for the post-volcanic autumns (Figure 6(a), (c) and (e)). Positive stratospheric anomalies and negative tropospheric anomalies related to the direct radiative volcanic forcing are seen in low latitudes. At high latitudes, significant negative geopotential height anomalies are found in the stratosphere and the troposphere south of $\sim 55-60^{\circ} \mathrm{S}$ in all three seasons, the 1991 anomalies being noticeably weaker. In ERA-40 (and also in the NNR, not shown) the geopotential height anomalies in low latitudes are similar to simulated ones, but in high latitudes they are the opposite.

The decreases in geopotential height at high latitudes and weak increases at mid-latitudes project onto the positive phase of the SAM. The positive SAM phase is seen in the simulated MSLP anomalies (Figure 7) averaged over the springs of 1982 and 1992 when the response appeared most pronounced according to Figure 5. In the multi-model mean the negative MSLP anomalies over the Antarctic exceed 1.5 standard deviations (SD) of the respective time series. All the individual models apart from the GISS-ER, MIROC3.2 (medres), and CCSM3.0 models simulate the anomalously low MSLP over the Antarctic.

\section{Discussion and Conclusions}

In the $\mathrm{NH}$ the dynamical response to volcanic eruptions is observed during winter when large-scale planetary waves are able to propagate from the troposphere to the stratosphere and transfer heat poleward. The response is usually interpreted as a manifestation of the zonal flow-planetary wave interactions (e.g. Graf et al., 1993). Heating of the tropical stratosphere by volcanic aerosols results in a stronger meridional temperature gradient which, consistent with thermal wind balance, translates to stronger stratospheric zonal winds. However this alone cannot explain the cooling of the high-latitude stratosphere. Kodera (1994) suggested that the stronger winds refract the planetary waves equatorward resulting in a reduced heat transport to the polar stratosphere and further leading to a stronger and colder polar vortex. The stratospheric anomaly propagates downward resulting in a positive NAM phase in the troposphere.

In the $\mathrm{SH}$, maximum planetary wave amplitudes in the polar stratosphere are observed in spring and late autumn (Randel, 1988) since strong zonal winds reduce wave propagation to the polar stratosphere in winter. The stratospheric SAM variability, which reflects the zonal flow-planetary wave interactions, exhibits a maximum in spring only (Thompson et al., 2005), but some studies (e.g. Farrara et al., 1992) also found strong zonal flow-planetary wave interactions in autumn-early winter in the SH. Here we show that climate models simulate a significant response of the SH circulation to volcanic forcing in spring and in autumn. The result is consistent with the zonal flow-planetary wave interaction mechanism proposed to explain the NH response, provided the seasonality of the $\mathrm{SH}$ stratospheric planetary waves, which are needed to amplify the dynamical response, is taken into account. Eddy meridional heat flux at $100 \mathrm{hPa}$, which is a traditional proxy of wave activity flux into the stratosphere, is shown in 

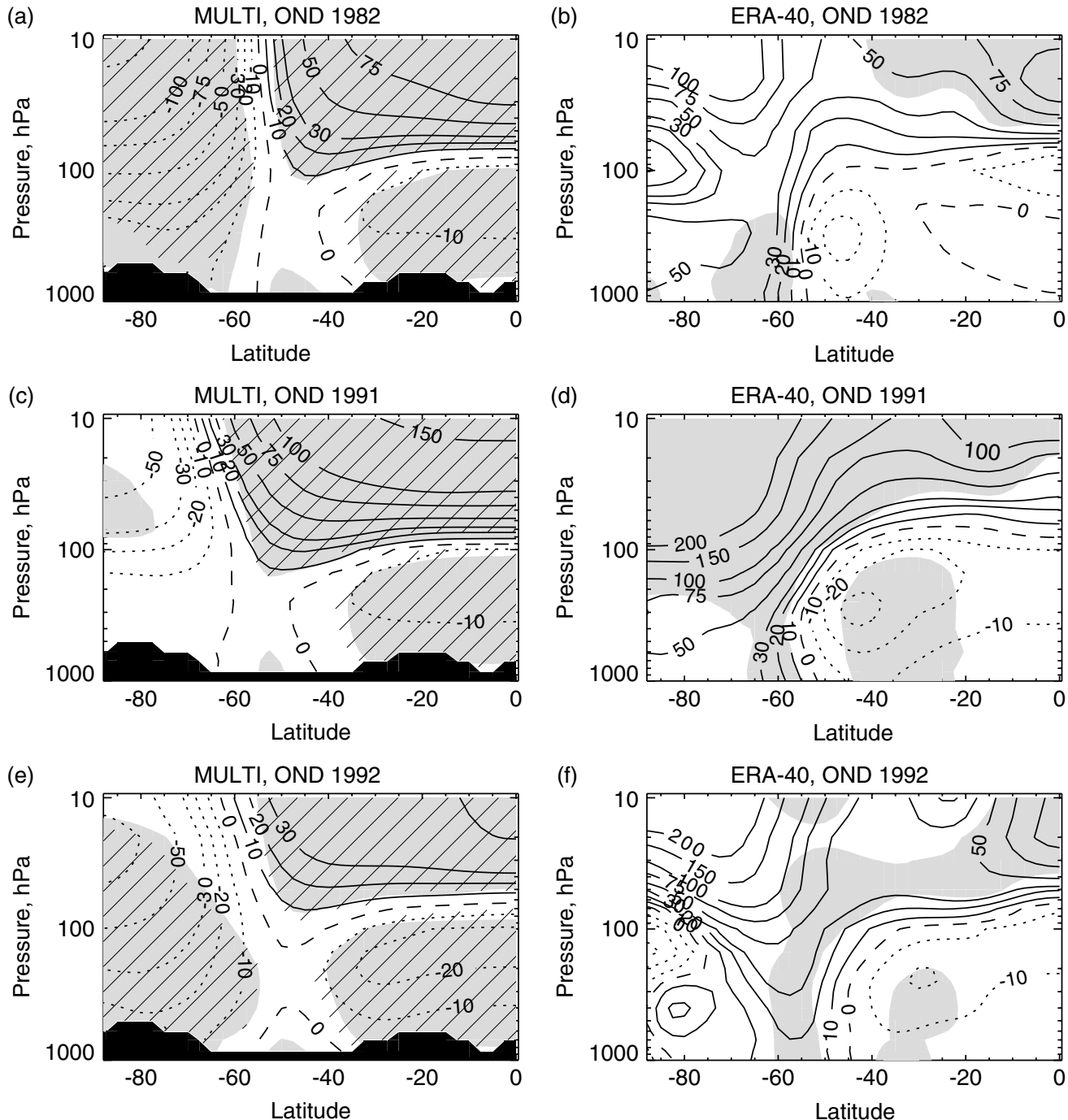

Figure 5. October-December mean detrended zonal mean geopotential height anomalies (m) for (a),(c),(e) MULTI and (b),(d),(f) ERA-40 for years (a) -(b) 1982, (c) -(d) 1991, and (e)-(f) 1992. Shading indicates areas where anomalies exceed 1.5 SD of the respective time series. Hatching in (a),(c),(e) indicates anomalies significant with $p<0.05$.

Figure 8(a). The flux, which for convenience is considered to be directed southward, exhibits a maximum in spring in the reanalyses and in the models, and also a weak secondary maximum in late autumn/early winter in the reanalyses and in some models. Wind and heat flux anomalies in the post-volcanic years are shown in Figure 9. To account for the cumulative effect of the eddy heat flux on the mean flow (Newman et al., 2001), the flux shown for a given month is averaged over that month and the two preceding months. Strong negative anomalies in the flux are seen in spring and a weaker one is seen in April, coinciding with maximum positive anomalies in the zonal wind. This supports the hypothesis that the seasonality of the response may be related to the seasonality of planetary waves propagating from the troposphere. (Note that since daily model data were not available, only the stationary component of the flux is shown; this limitation should be kept in mind when interpreting the results.) This seasonality in stratosphere-troposphere coupling may also explain why Robock et al. (2007) found no dynamical response to the Pinatubo eruption in the $\mathrm{SH}$ in winter when planetary wave propagation from the troposphere to the stratosphere is weakened.
Why is the simulated polar stratosphere response inconsistent with the reanalyses in spring? Stenchikov et al. (2006) found that the simulated stratospheric zonal winds in the $\mathrm{NH}$ are stronger than those in the reanalyses and argued that this might explain the weaker magnitude of the simulated volcanic response in the NH. They suggested that the too-strong simulated polar vortex may be unrealistically resistant to penetration by planetary waves. However, Figure $8(\mathrm{~b})$ shows that the simulated $\mathrm{SH}$ winds are in a reasonable agreement with the reanalyses. On the other hand the simulated eddy heat flux is smaller than that in the reanalyses in spring, especially in October when the fluxes in the reanalyses fall outside the $5-95 \%$ confidence intervals calculated across the simulated fluxes. It is not clear whether this difference is related to the different volcanic responses. One may speculate, based on the results from a simple one-dimensional model of the wave-zonal mean flow interaction (e.g. Holton and Dunkerton, 1978), that a weaker wave flux from the troposphere is more sensitive to the changes in differential heating due to volcanic aerosol than a stronger wave flux, because in the former case the increase in zonal winds due to anomalous differential heating is more likely to result in conditions unfavourable for vertical wave propagation, provided that the undisturbed zonal flow 
(a)

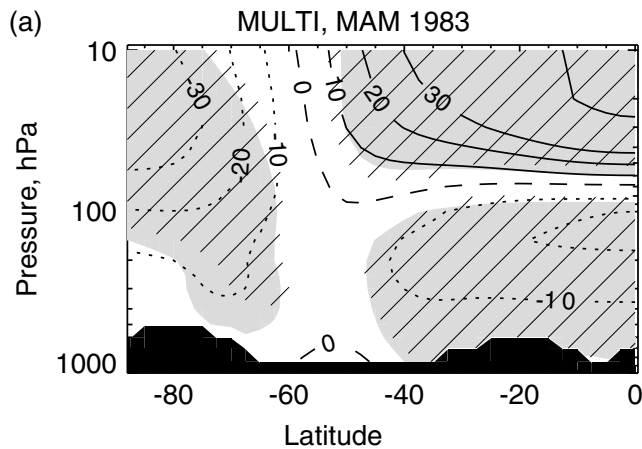

(c)

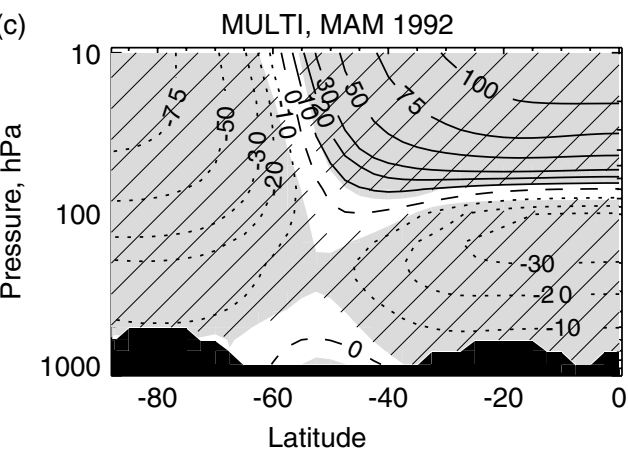

(e)

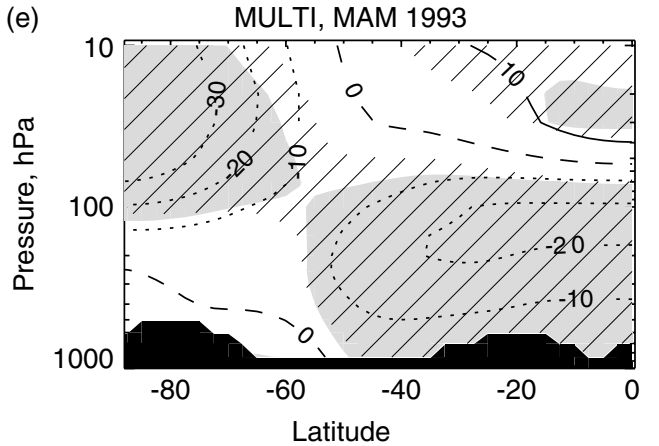

(b)

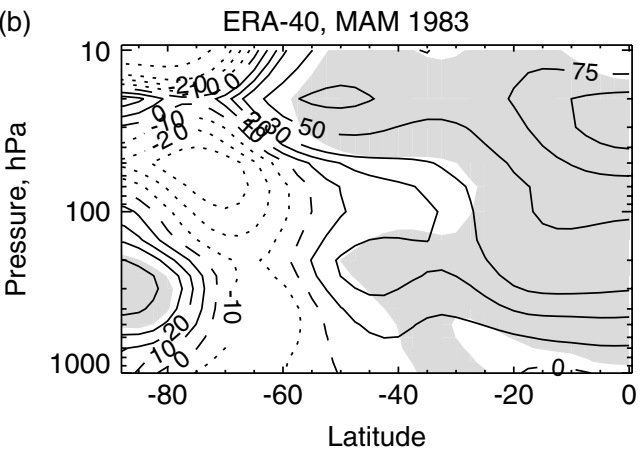

(d)

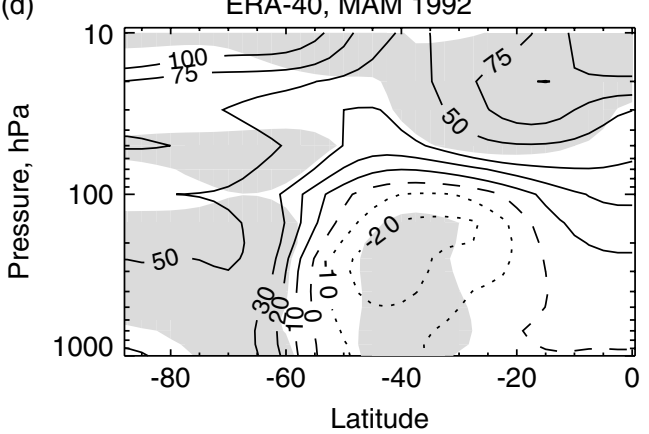

(f)

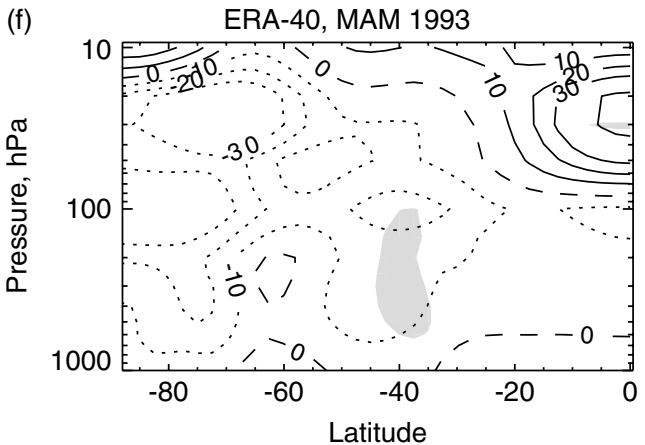

Figure 6. The same as Figure 5 but for March-May.

is supportive for the propagation. This interpretation may be applied if the reason for the weaker simulated flux is a weaker tropospheric source, but it may not be applied if the reason is an unrealistically large damping of the planetary waves in the stratosphere in these models.

The extratropical MSLP anomalies in the ERA-40 reanalysis (Figure 7) project on the negative SAM phase, which has been shown to occur during El Niño events (e.g. L'Heureux and Thompson, 2006). The circulation anomalies associated with the El Niño events occurring after the eruptions (see Figure 1) may oppose the dynamical volcanic response in the real atmosphere. To test this hypothesis we calculated the El Niño signal by regressing the El Niño 3.4 index on the $\mathrm{SH}$ polar cap $50 \mathrm{hPa}$ geopotential height in spring, when the simulated volcanic response is inconsistent with the reanalyses, and removed the signal from the simulations and the reanalyses. The El Niño signal in the reanalyses is small and accounts for about $2 \%$ of the $\mathrm{SH}$ polar cap geopotential height variability at $50 \mathrm{hPa}$. After removal of the El Niño signal the difference between the models and the reanalyses still appeared significant with $p<0.05$. Although the extratropical circulation could be linked to El Niño in a complicated nonlinear way, such a link is difficult to quantify. On the other hand, the linear approach provides no evidence that the different volcanic response is attributable to the El Niño influence.

Further factors that are likely to influence the volcanic response but are not well represented in current climate models are: (1) the QBO in equatorial winds which is known to influence midlatitude wave propagation (Baldwin et al., 2001), and (2) ozone depletion following the eruption, which cools the lower tropical stratosphere and hence moderates the direct radiative signal at the Equator. Stenchikov et al. (2004) showed that the easterly QBO phase cooled the tropical stratosphere during the first year after the Pinatubo eruption leading to a smaller warming than that expected from the aerosols' heating only. However we find that the simulated warming after both the eruptions is not inconsistent with the reanalyses throughout most of the lower stratosphere. This suggests that the difference in the tropical stratosphere response is unlikely to explain the different dynamical response. Further, the six-member HadGEM1 QBO ensemble shows a weakened MLSP signal when compared with the standard HadGEM1 response, but still has the opposite sign to the ERA-40 distribution (Figure 7). Similar to MULTI, this ensemble shows a strengthened $\mathrm{SH}$ polar stratospheric vortex after the eruptions (Figure 1(c)), although this response is only significant in autumn $(p<0.05)$. 

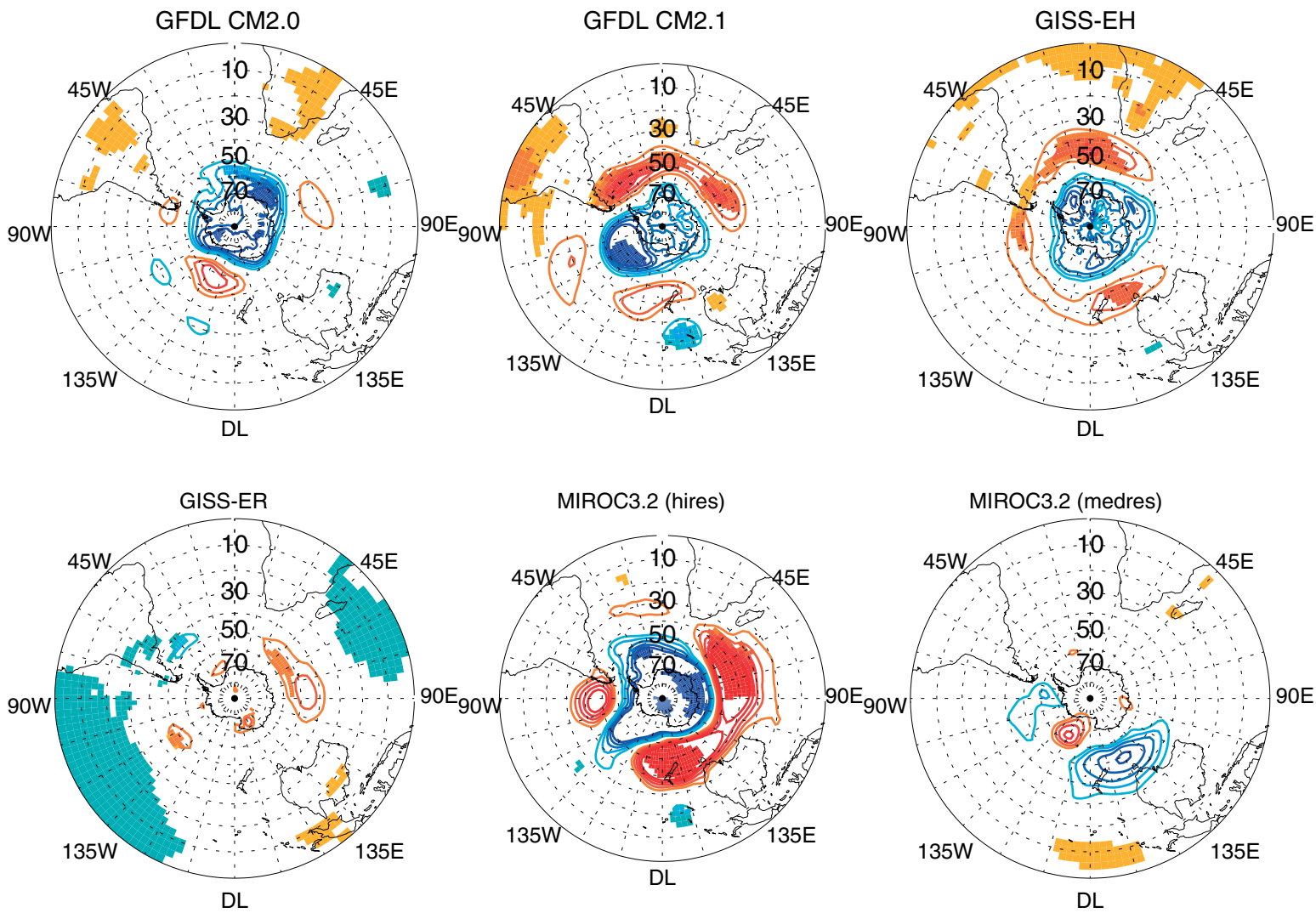

MIROC3.2 (hires)

MIROC3.2 (medres)
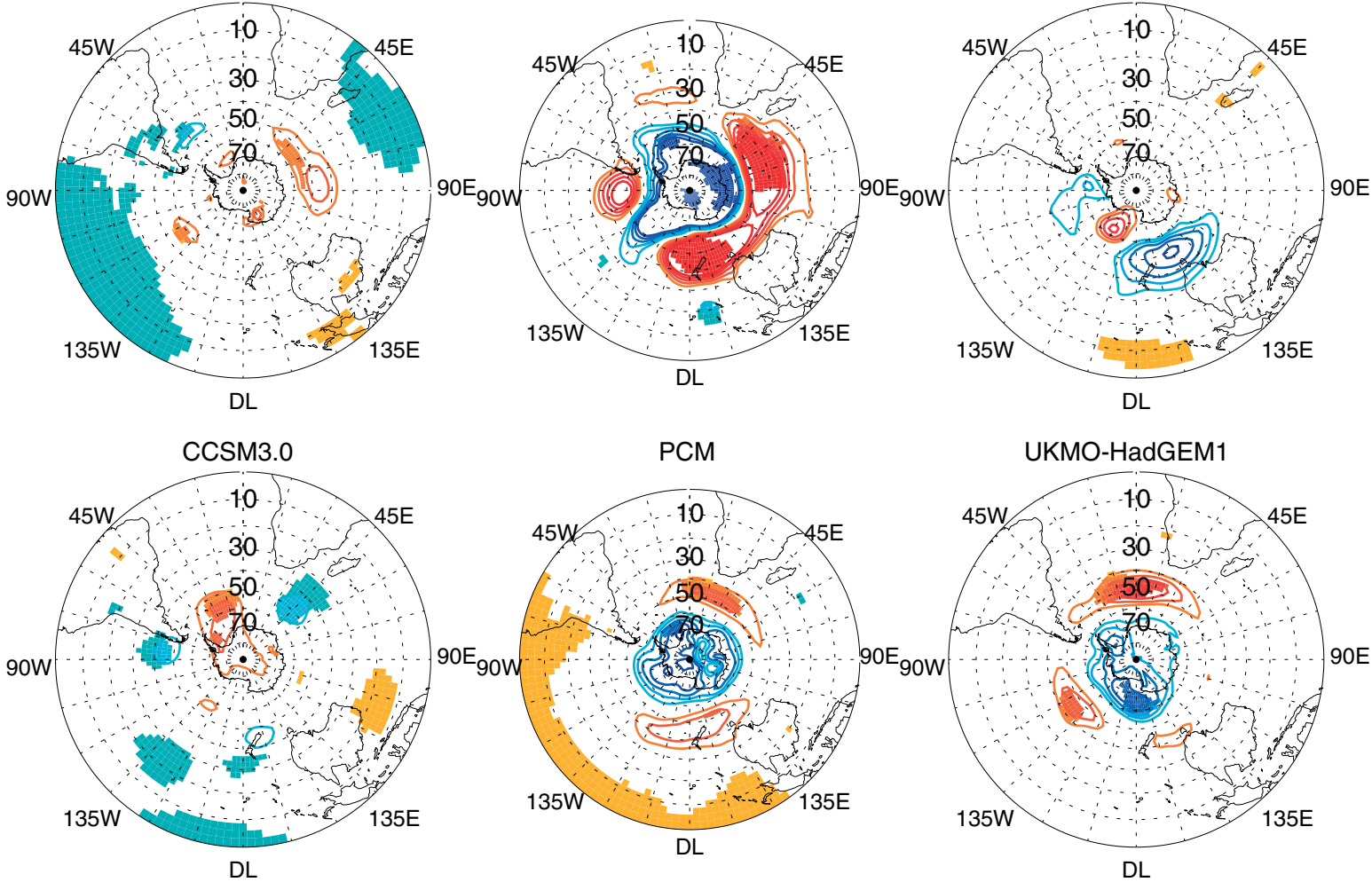

UKMO-HadGEM1 (QBO)

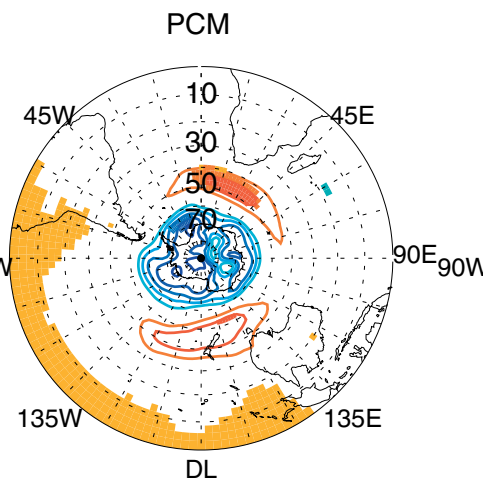

UKMO-HadGEM1

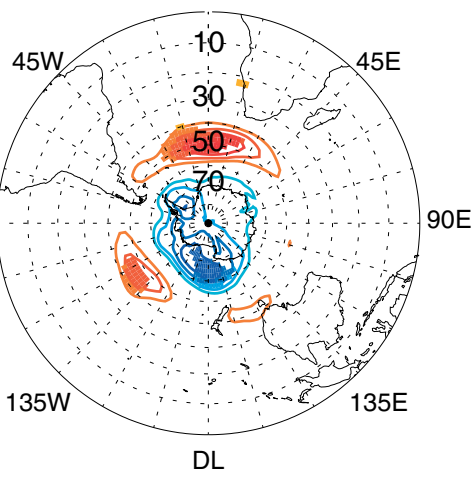

MULTI

ERA-40

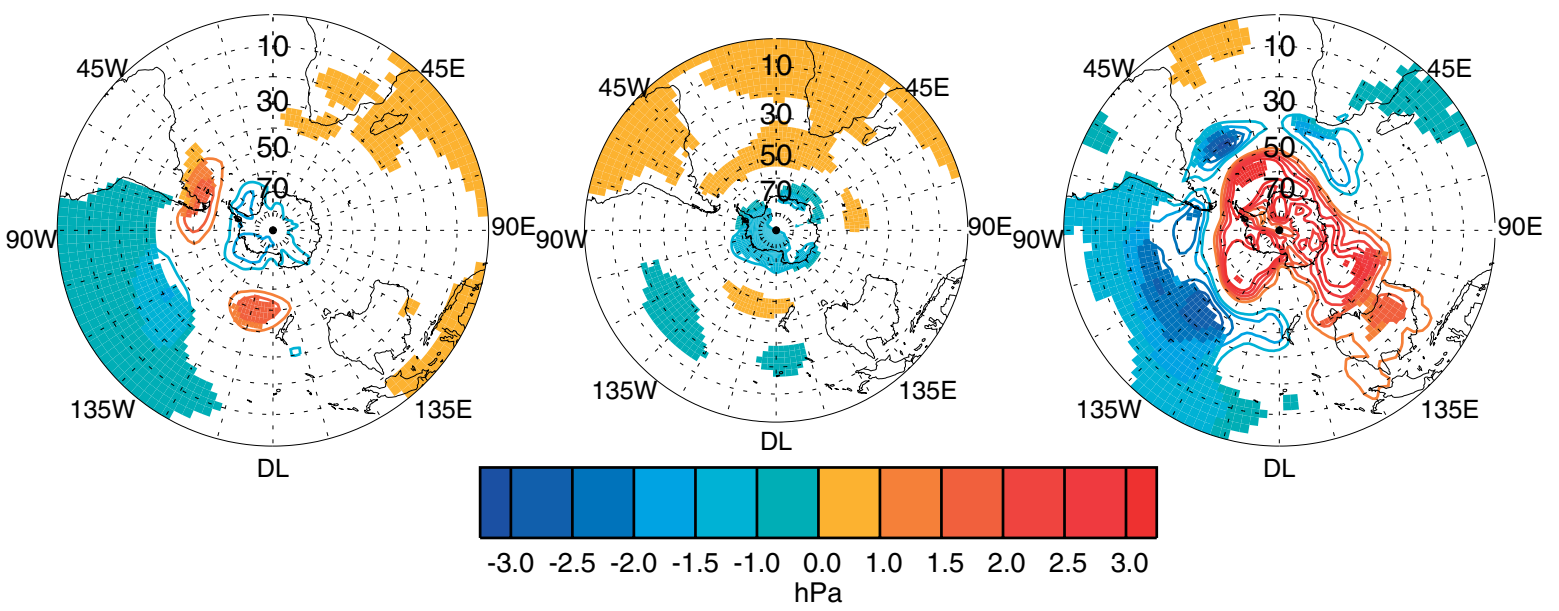

Figure 7. October-December mean detrended MSLP anomalies averaged over years 1982 and 1992 for individual models, multi-model ensemble mean (MULTI) and ERA-40. Only areas where anomalies exceed 1.5 SD of the respective time series are filled. 
(a)
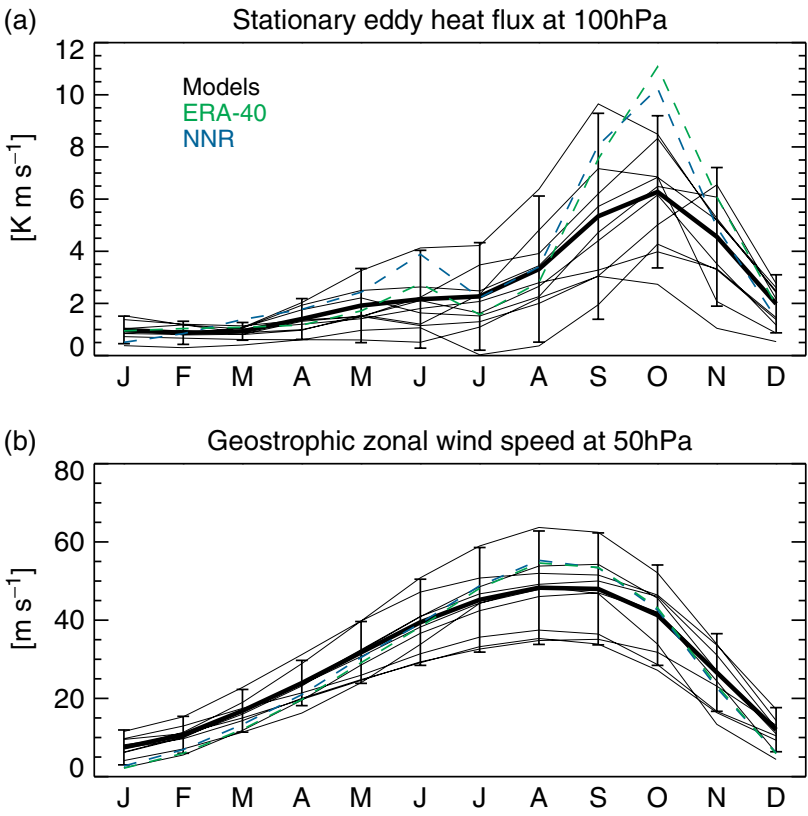

Figure 8. Seasonal behaviour of (a) $100 \mathrm{hPa}$ stationary eddy heat flux averaged over $50-70^{\circ} \mathrm{S}$ and multiplied by -1 so that it is directed southward; and (b) $50 \mathrm{hPa}$ geostrophic zonal mean zonal wind averaged over $50-65^{\circ} \mathrm{S}$ Individual models are marked by the thin black lines and MULTI is marked by the thick black lines. The reanalyses are marked by the dashed lines. Error bars indicate 5-95\% confidence intervals for MULTI based on the all-model simulations. This figure is available in colour online a wileyonlinelibrary.com/journal/qj

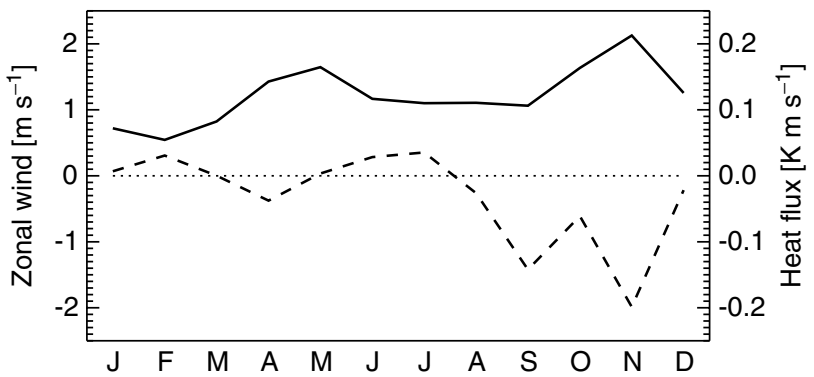

Figure 9. Anomalous $50 \mathrm{hPa}$ geostrophic zonal mean zonal wind averaged over $50-65^{\circ} \mathrm{S}$ (solid) and anomalous $100 \mathrm{hPa}$ stationary southward eddy heat flux averaged over $50-70^{\circ} \mathrm{S}$ (dashed) in the post-volcanic years in MULTI. The heat flux shown for each month is averaged over that month and the two preceding months.

The ozone forcing in the HadGEM1 QBO simulations includes observed interannual variability, but some satellite data were missing following the two eruptions (Dall'Amico et al., 2009a, their Appendix A). However Rozanov et al. (2002) in chemistry-climate model simulations found that the volcano-induced tropical ozone depletion is rather small and unlikely to provide a considerable cooling. Therefore model deficiency in representing the tropical ozone depletion is unlikely to explain the difference between the simulated and observed responses in the $\mathrm{SH}$ high latitudes.

The effects of volcanic eruptions detected here in model simulations may be useful in forecasting the climate response to future eruptions or possibly artificial injection of aerosol into the stratosphere. Therefore it is important to understand the reasons for the different dynamical responses between the models and the reanalyses. Given the small size of the observational sample (four seasons), the power of our consistency tests is low. It is plausible that the enhanced planetary wave propagation from the troposphere to the stratosphere which caused the positive anomalies in observed stratospheric geopotential height fields, thus biasing the observational sample, is related to modes of internal climate variability other than $\mathrm{El} \mathrm{Niño.} \mathrm{Factors} \mathrm{that}$ control the variability of the $\mathrm{SH}$ stratosphere need to be understood better. Also the role of QBO, ozone depletion and El Niño in modulating the SH high-latitude response to volcanic eruptions needs to be investigated in models more suitable for stratospheric studies than the CMIP3 models, the majority of which have a poorly resolved stratosphere (e.g. Cordero and Forster, 2006). Given the low signal-tonoise ratio, the size of simulation ensembles in such studies needs to considerably exceed the size of the HadGEM1-QBO ensemble (six members) available for the present study.

\section{Acknowledgements}

This work is supported by NERC Project NE/E006787/1. AK was partly supported by the Finnish Academy. We acknowledge the modelling groups, the Program for Climate Model Diagnosis and Intercomparison (PCMDI) and the WCRP's Working Group on Coupled Modelling (WGCM) for their roles in making available the WCRP CMIP3 multimodel dataset. Support of this dataset is provided by the Office of Science, US Department of Energy. We thank Gareth Marshall and Stefan Brönnimann whose questions stimulated this study and two anonymous reviewers for useful suggestions.

\section{References}

Ammann CM, Meehl GA, Washington WM, Zender CS. 2003. A monthly and latitudinally varying volcanic forcing dataset in simulations of 20th century climate. Geophys. Res. Lett. 30: 1657, DOI:10.1029/2003GL016875.

Baldwin MP, Gray LJ, Dunkerton TJ, Hamilton K, Haynes PH, Randel WJ, Holton JR, Alexander MJ, Hirota I, Horinouchi T, Jones DBA, Kinnersley JS, Marquardt C, Sato K, Takahashi M. 2001. The quasi-biennial oscillation. Rev. Geophys. 39: 179-229.

Cordero EC, Forster PMDeF. 2006. Stratospheric variability and trends in models used for the IPCC AR4. Atmos. Chem. Phys. 6: 5369-5380.

Crooks SA, Gray LJ. 2005. Characterization of the 11-year solar signal using a multiple regression analysis of the ERA-40 dataset. J. Climate 18: $996-1015$.

Dall'Amico M, Gray LJ, Rosenlof KH, Scaife AA, Shine KP, Stott PA. 2010a. Stratospheric temperature trends: Impact of ozone variability and the QBO. Clim. Dyn. 34: 381-398.

Dall'Amico M, Stott PA, Scaife AA, Gray LJ, Rosenlof KH, Karpechko AYu. 2010b. Impact of stratospheric variability on tropospheric climate change. Clim. Dyn. 34: 399-417.

Farrara JD, Fisher M, Mechoso CR, O’Neill A. 1992. Planetary-scale disturbances in the southern stratosphere during early winter. $J$. Atmos. Sci. 49: 1757-1775.

Graf H-F, Kirchner I, Robock A, Schult I. 1993. Pinatubo eruption winter climate effects: Model versus observations. Clim. Dyn. 9: 81-93.

Holton JR, Dunkerton TJ. 1978. On the role of wave transience and dissipation in stratospheric mean flow vacillations. J. Atmos. Sci. 35: $740-744$.

Kalnay E, Kanamitsu M, Kistler R, Collins W, Deaven D, Gandin L, Iredell M, Saha S, White G, Woollen J, Zhu Y, Chelliah M, Ebisuzaki W, Higgins W, Janowiak J, Mo KC, Ropelewski C, Wang J, Leetmaa A, Reynolds R, Jenne R, Joseph D. 1996. The NCEP/NCAR 40-year reanalysis project. Bull. Am. Meteorol. Soc. 77: 437-471.

Kirchner I, Stenchikov GL, Graf H-F, Robock A, Antuña JC. 1999. Climate model simulation of winter warming and summer cooling following the 1991 Mount Pinatubo volcanic eruption. J. Geophys. Res. 104: 19039-19055.

Kodera K. 1994. Influence of volcanic eruptions on the troposphere through stratospheric dynamical processes in the Northern Hemisphere winter. J. Geophys. Res. 99: 1273-1282. 
L'Heureux ML, Thompson DWJ. 2006. Observed relationships between the El Niño-Southern Oscillation and the extratropical zonal-mean circulation. J. Climate 19: 276-287.

Marshall GJ. 2003. Trends in the Southern Annular Mode from observations and reanalyses. J. Climate 16: 4134-4143.

Newman PA, Nash ER, Rosenfield JE. 2001. What controls the temperature of the Arctic stratosphere during the spring? J. Geophys. Res. 106: 19999-20010.

Ramachandran S, Ramaswamy V, Stenchikov GL, Robock A. 2000. Radiative impact of the Mount Pinatubo volcanic eruption: Lower stratospheric response. J. Geophys. Res. 105: 24409-24429.

Randel WJ. 1988. The seasonal evolution of planetary waves in the Southern Hemisphere stratosphere and troposphere. Q. J. R. Meteorol. Soc. 114: 1385-1409.

Rayner NA, Parker DE, Horton EB, Folland CK, Alexander LV, Rowell DP, Kent EC, Kaplan A. 2003. Global analyses of sea surface temperature, sea ice, and night marine air temperature since the late nineteenth century. J. Geophys. Res. 108: 4407, DOI:10.1029/2002JD002670.

Robock A. 2000. Volcanic eruptions and climate. Rev. Geophys. 38: 191-219.

Robock A, Adams T, Moore M, Oman L, Stenchikov GL. 2007. Southern Hemisphere atmospheric circulation effects of the 1991 Mount Pinatubo eruption. Geophys. Res. Lett. 34: L23710, DOI:10.1029/2007GL031403.

Roscoe HK, Haigh JD. 2007. Influences of ozone depletion, the solar cycle and the QBO on the Southern Annular Mode. Q. J. R. Meteorol. Soc. 133: 1855-1864.

Rozanov EV, Schlesinger ME, Andronova NG, Yang F, Malyshev SL, Zubov VA, Egorova TA, Li B. 2002. Climate/chemistry effects of the Pinatubo volcanic eruption simulated by the UIUC stratosphere/troposphere GCM with interactive photochemistry. J. Geophys. Res. 107: 4594, DOI:10.1029/2001JD000974.
Sato M, Hansen JE, McCormick MP, Pollack JB. 1993. Stratospheric aerosol optical depths, 1850-1990. J. Geophys. Res. 98: 22987-22994. Stenchikov GL, Kirchner I, Robock A, GrafH-F, Antuña JC, Grainger RG, Lambert A, Thomason L. 1998. Radiative forcing from the 1991 Mount Pinatubo volcanic eruption. J. Geophys. Res. 103: 13837-13857.

Stenchikov GL, Hamilton K, Robock A, Ramaswamy V, Schwarzkopf MD. 2004. Arctic Oscillation response to the 1991 Pinatubo eruption in the SKYHI general circulation model with a realistic quasi-biennial oscillation. J. Geophys. Res. 109: D03112, DOI:10.1029/2003JD003699.

Stenchikov GL, Hamilton K, Stouffer RJ, Robock A, Ramaswamy V, Santer B, Graf H-F. 2006. Arctic Oscillation response to volcanic eruptions in the IPCC AR4 climate models. J. Geophys. Res. 111: D07107, DOI:10.1029/2005JD006286.

Thompson DWJ, Wallace JM. 2000. Annular modes in the extratropica circulation. Part I: Month-to-month variability. J. Climate 13 1000-1016.

Thompson DWJ, Baldwin MP, Solomon S. 2005. Stratosphere-troposphere coupling in the Southern Hemisphere. J. Atmos. Sci. 62: 708-715.

Turner J. 2004. Review: The El Niño-Southern Oscillation and Antarctica. Int. J. Climatol. 24: 1-31.

Uppala SM, Kållberg PW, Simmons AJ, Andrae U, Da Costa Bechtold V, Fiorino M, Gibson JK, Haseler J, Hernandez A, Kelly GA, Li X, Onogi K, Saarinen S, Sokka N, Allan RP, Andersson E, Arpe K, Balmaseda MA, Beljaars ACM, Van De Berg L, Bidlot J, Bormann N, Caires S, Chevallier F, Dethof A, Dragosavac M, Fisher M, Fuentes M, Hagemann S, Hólm E, Hoskins BJ, Isaksen L, Janssen PAEM, Jenne R, McNally AP, Mahfouf J-F, Morcrette J-J, Rayner NA, Saunders RW, Simon P, Sterl A, Trenberth KE, Untch A, Vasiljevic D, Viterbo P, Woollen J. 2005. The ERA-40 re-analysis. Q. J. R. Meteorol. Soc. 131 2961-3012. 